\title{
Capítulos Fotográficos no Centro da Fortaleza Transitória
}

\author{
Daniel Paiva de Macêdo Júnior Faculdade de Filosofia e Ciências Humanas, Universidade \\ Federal de Minas Gerais, Belo Horizonte, Brasil \\ https://orcid.org/0000-0002-1415-7792 \\ Elian Castro de Machado \\ Instituto de Cultura e Arte, Universidade Federal do Ceará, \\ Fortaleza, Brasil https://orcid.org/0000-0002-2463-0344
}

\section{Photographic Chapters in the Centre of Transient Fortaleza}

Submetido: 13/04/2021 | Revisto: 19/04/2021 | Aceite: 03/05/2021 | Publicado: 29/07/2021

Fortaleza é uma cidade brasileira que reúne uma população superior a 2.500 .000 de habitantes, produzindo a marca de 7.786,44 hab $/ \mathrm{km}^{2}$, o que a faz figurar como a cidade de maior densidade demográfica de entre as capitais brasileiras (Instituto Brasileiro de Geografia e Estatística [IBGE], 2010) e posicionar-se entre as 10 metrópoles urbanas do país (IBGE, 2018). Somos um porto margeado em profunda desigualdade, exposta nas diferenças observadas no índice de desenvolvimento humano (IDH; Fundação Demócrito Rocha, 2021): o bairro Meireles possui um IDH de 0,953 - superior ao da Noruega $(0,944)$ que ocupa o primeiro lugar no ranking mundial e o bairro Praia do Futuro II alcança um IDH de 0,167 - inferior ao do Niger $(0,348)$, situado como último da lista de países.

O centro é parte de Fortaleza e, componente de uma metrópole brasileira, está permeado por distintos interesses que o vislumbram como um destino inventado na composição do cartão postal construído para o mercado do turismo; em detrimento das dinâmicas cotidianas que articulam e dinamizam o espaço urbano. Diante da friç̧ão de imaginários sobre o território e cientes do lugar da produção imagética na construção de memória social, esta pesquisa é desenvolvida em ação de campo orientada por vínculos de proximidade (Magnani, 2008), a fim de tomar notas e de constituir inscrições fotográficas para, partindo destas, à luz dos ensinamentos de Martins (2016), compor poéticas visuais sobre o espaço em disputa.

Nesta dinâmica, o centro da cidade é um ponto de partilha e de experiência coletiva no território complexificado que compõe a metrópole. No limiar de interesses e de diferentes usos do espaço, trata-se de uma área em constante disputa: seja nas batalhas jurídicas que definem os rumos legais daquele lugar, seja nas batalhas simbólicas para a composição de um imaginário sobre o local. Sendo o centro um locus coletivo, converge a composição de uma fotografia panorâmica de Fortaleza e de suas contradições.

As disputas que engendram uma capital em movimento como Fortaleza não se isolam nas instâncias deliberativas do Estado, mas se praticam nas expressões cotidianas que posicionam embates narrativos orientados para um projeto de hegemonia na cidade. É nas trocas simbólicas, na constituição de desejos coletivos sobre o local em que vivemos, onde reside uma importante mola propulsora das mudanças no território. Afinal, fruto de contradições, uma cidade - enquanto produto social - é experienciada na interação dos sujeitos com o espaço, sob mediação das relações de poder. É, em outras palavras, objeto de disputa no campo do imaginário.

Distribuídos em territórios que se estendem do litoral às periferias, os povos de Fortaleza constituem, (re)criam e se inserem na produção das urbanidades não somente através da ocupação das zonas públicas; mas, também, através da produção fotográfica como experiência cotidiana, a partir dos ritos de registro visual, que se constituem em artefatos importantes para a construção de imaginários radicados na vivência comunitária; que revela o contraste com as visualidades 
construídas pelos discursos evocados pelos agentes da economia do turismo. Portanto, temos nas imagens um importante depoimento "das tensões e do invisível nas ocultações" que as configuram objeto de interesse sociológico (Martins, 2016, p. 61) e que tornam tangíveis os discursos e as intencionalidades sobre o elemento documentado.

Considerando o contexto contemporâneo de disputa simbólica para a constituição de uma imagem pública sobre o centro de Fortaleza, esta pesquisa se desenvolve no intento de discutir o local conferido ao fotógrafo na constituição de imagens sobre um espaço entremeado por oposições de ordem social, econômica e estética e em meio ao complexo ecossistema midiático de nossos tempos. Para isto, realizámos um exercício de pesquisa de campo, com inspiração antropológica em Magnani (2008), que defende a proximidade com o território. Assim, tomámos a fotografia como método para inscrição das afetações, segundo Martins (2016). A produção fotográfica se realiza, nestes marcos, com atenção à ação do flanêur, como proposto por Walter Benjamin (1985/1994, p. 34), sob a tese de que o espaço público produz arranjos imagéticos que, resultado da experiência comum, posicionam uma perspectiva sobre os usos e ocupações do locus. Sendo assim, o fotógrafo é um sujeito cambiante no espaço em interação com outros agentes para, fruto de uma ação transitória, referenciar os registros das cenas que exprimem lógicas de uso, de ocupação e de imaginação sobre o espaço. Como gesto de valorização das memórias e dos atravessamentos na ação fotográfica, tomámos os registros como basilares na prática de pesquisa em campo. Para isso, é justo desnudar-se de compreensões monolíticas sobre o local e que o reduzem a linearidade, a homogeneidade. Nesta via, adotámos como preceito teórico-metodológico a iniciativa de abrir o peito à ventania e de deixar viver os ensinamentos do campo de pesquisa e dos sujeitos que também se permitiram à interação. Deste modo, nos guiámos pela intervenção que desmonta o lugar de diferença imposto pela alcunha de "jornalista" e de "fontes" ao assumir o local que nos é próprio enquanto sujeitos transitórios pertencentes a Fortaleza e ao demarcar o ato fotográfico como ação comum, que compõe a ritualística contemporânea em zonas de consumo.

Bebemos da leitura compartilhada por Martins (2016) onde "não há pesquisa sociológica e nem antropológica sem interação entre o pesquisador e as populações que estuda" (p. 12). Entendemos a dinâmica de produção fotográfica como ato compartilhado entre os diversos agentes envolvidos sob lógicas e finalidades distintas, sendo o registro a síntese desta relação. Deste modo, o percurso metodológico é composto por temporadas de pesquisa de campo, ocorridas entre 2014 e 2018, no centro de Fortaleza. Ao recolher fotografias em vários momentos, pretendíamos conjugar registros na mesma espacialidade sob diferentes situações e, assim, perceber os elementos comuns e os perfis a comporem com maior constância uma perspectiva cotidiana a partir da experiência.

Buscámos, assim, a partir da ação do flanêur, em diferentes momentos, no intervalo de 4 anos, identificar no registro as práticas de uso e de ocupação dos espaços e os sujeitos que rompem com o tempo e com o efêmero ao se firmarem partes constantes e, em igual peso, transitórias no locus. Assim, não nos interessa a representação pontual de eventos ocorridos em um único momento da pesquisa de campo; mas, na complexidade da variedade permitida em diferentes vivências de ação e de registro, identificar os pontos expressivos de lógicas que tecem o cotidiano. A característica complexa de inserção em espaço urbano, em constante transformação ao longo dos anos, por sua vez, constitui um elemento que posiciona o olhar analítico que diferencia esta pesquisa de outros intentos de natureza jornalística ou artística desenvolvidos no mesmo espaço.

Tomar parte importante da urbe como objeto de atenção fotográfica posiciona este trabalho no fluxo da cena contemporânea que, em detrimento da larga tradição documental cearense, onde "a cidade e a cultura urbana pareciam não existir, não ter vida no mundo das imagens" (Reis Filho, 2017, p. 111), passa a compor o foco de projeção.

A prática de campo consistiu em visitas de registro, sempre munidas de uma Nikon D5100 e duas lentes, sendo uma AF-S DX NIKKOR 18-140mm f/3.5-5.6G de oscilação de grande angular à telefoto e outra AF NIKKOR 50mm f/1-1.8D. Adotando o que chamamos neste trabalho de fotografia transitória, percorremos trajetos múltiplos no bairro central considerando sempre o alcance de 
locais de atravessamento, espaços públicos e de convívio social; dos quais selecionámos a Praça do Ferreira, o Theatro José de Alencar, as igrejas de múltiplas religiões ali presentes, o Centro Cultural Dragão do Mar e o conjunto de ruas e avenidas que tecem o emaranhado urbano. Na pesquisa de campo, foram produzidos registros sem fixar-nos em um ponto e, na medida que compunha o território, registrávamos os perfis e as ambiências que eram percebidos como visualidades transitórias - logo, constituintes em instâncias práticas e simbólicas do local registrado. Aqui, vale a "observação imediata" do objeto a ser enquadrado pelo proposto por Benjamin (1985/1994, p. 103) e, por consequência, a ação orientada para obter registros que, efêmeros, conjuguem a poética única da ação e das rupturas cotidiana e, à luz da responsabilidade histórica, versar sobre o que percebemos comum e que não ocupa assento nos documentos oficiais e na imagem pública do centro, construída pelo Estado e pelo empresariado.

Cientes do local social e epistêmico que ocupámos nos becos e vielas do centro enquanto jornalistas que exprimem na fotografia ação de pesquisa, partilhamos da compreensão que os registros ali produzidos são ficções mediadas "pelo tempo da fotografia, pelo olhar e pela situação social do próprio fotógrafo, por aquilo que ele socialmente representa e pensa" (Martins, 2016, p. 66). Em outras palavras, entendemos que a ação neste estudo é incapaz de exprimir em poéticas visuais a totalidade complexa do perímetro urbano de Fortaleza, mas confirma um ângulo particular praticado no espaço, em partilha com os sujeitos ocupantes das ruas e pelo qual a experiência permite tecer reflexões sobre o local do fotógrafo diante do emaranhado urbano e das práticas de poder simbólico.

Assumimos, portanto, posicionamentos, entendendo que o enquadramento de natureza estética e o de ordem política advogam uma perspectiva espacial, um ângulo delimitado na ação fotográfica. No total, foram 475 imagens distintas resultantes de curadoria sobre o campo; com ênfase nos sujeitos transitórios a fim de, resultante da experiência de partilha, compormos uma perspectiva visual sobre o território.

Tomando notas dos espaços transitados, debruçamo-nos sobre o total de fotografias organizando-as narrativamente quanto ao locus de registro. Uma vez agrupadas sobre o critério de locais comuns, o conjunto de fotografias passa por um segundo olhar a fim de identificar as práticas registradas e os perfis recorrentes inerentes a cada espacialidade, nos termos propostos por Magnani (2008), que nos lega pistas sobre o uso da fotografia para desenvolvimento de um saber antropológico sobre urbanidades.

Nisto, temos nas imagens uma curadoria que, sob a lupa praticada na pesquisa, constitui uma perspectiva sobre experiências possíveis no centro de Fortaleza. Logo, não buscámos o espetacular ao compor uma poética visual sobre o território, mas procurámos evidenciar o resultado da ação de pesquisa e as premissas de observação que o campo nos mostrou ao longo do largo período de pesquisa. São, portanto, mais que depoentes de escolhas curatoriais artísticas, pois, sob rigor da análise, têm por prioridade constituir-se como uma perspectiva da cidade em meio do complexo processo de disputa de narrativas sobre a urbe.

Assim, as fotografias sobre a Praça do Ferreira, o Theatro José de Alencar, o Centro Cultural Dragão do Mar e as diversas ruas, avenidas, becos e vielas do centro aqui expressas são a síntese da análise do conjunto de imagens que, sob a nossa perspectiva de experiência em campo, exprimem uma vista possível sobre a cidade. 


\section{Vista}

461. N. 8 (2021): Julho - dezembro 2021 | https://doi.org/10.21814/vista.3389

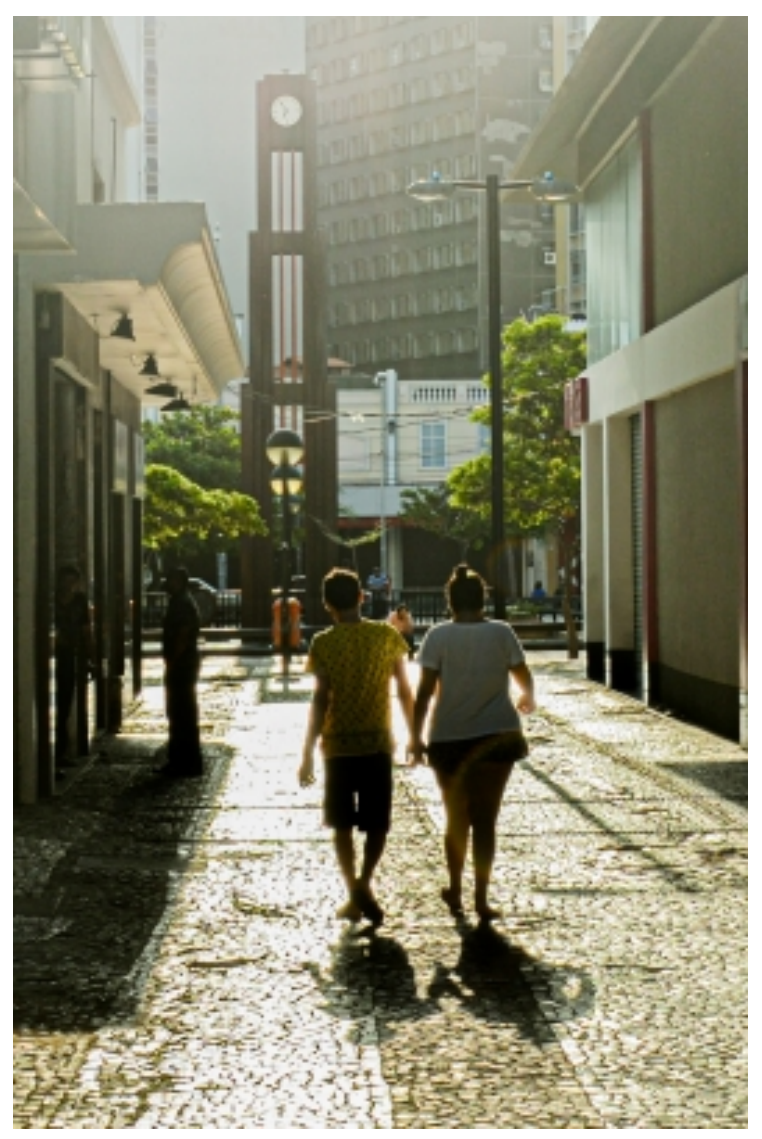

Figura 1. Desanuviar dias despertando no centro Acervo de Pesquisa/Daniel Macêdo, 2015

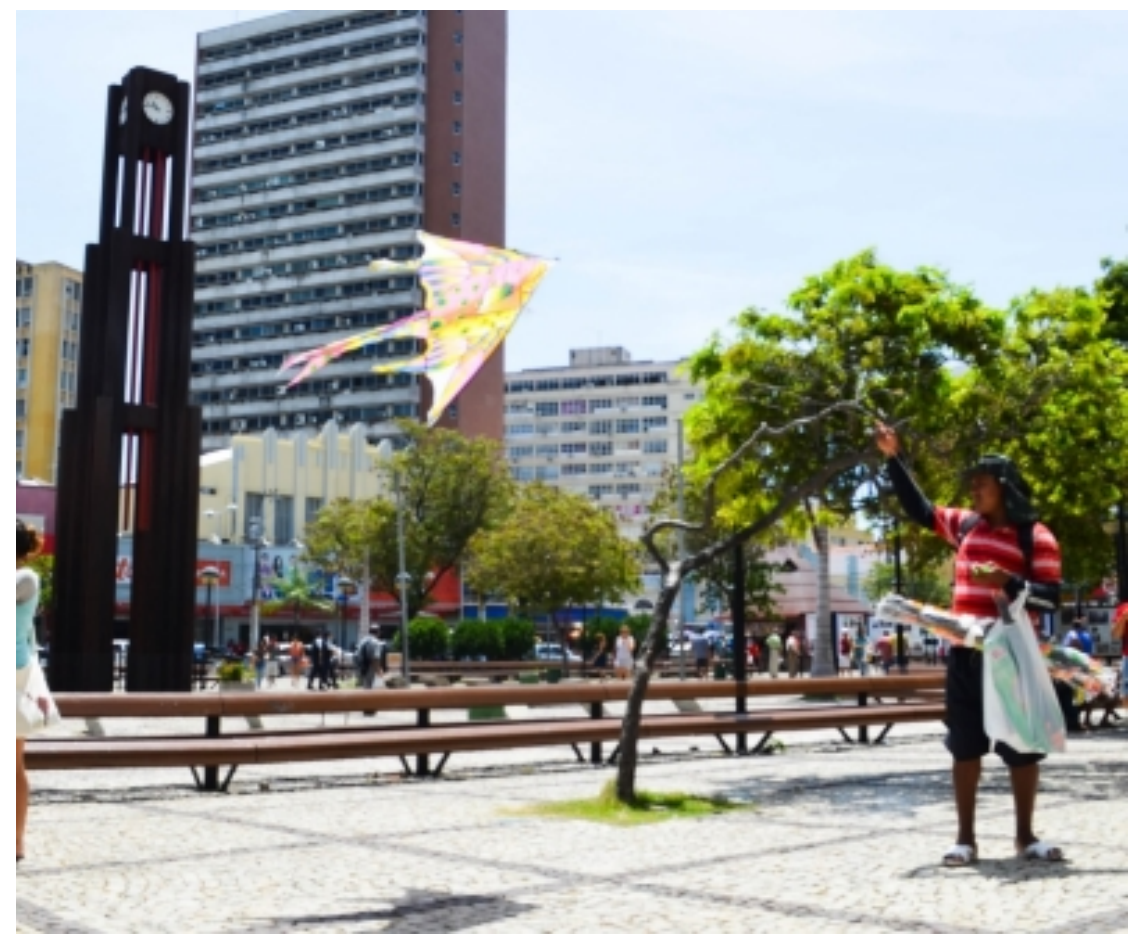

Figura 2. Velejar o Ferreira Acervo de Pesquisa/Daniel Macêdo, 2014 


\section{Vista}

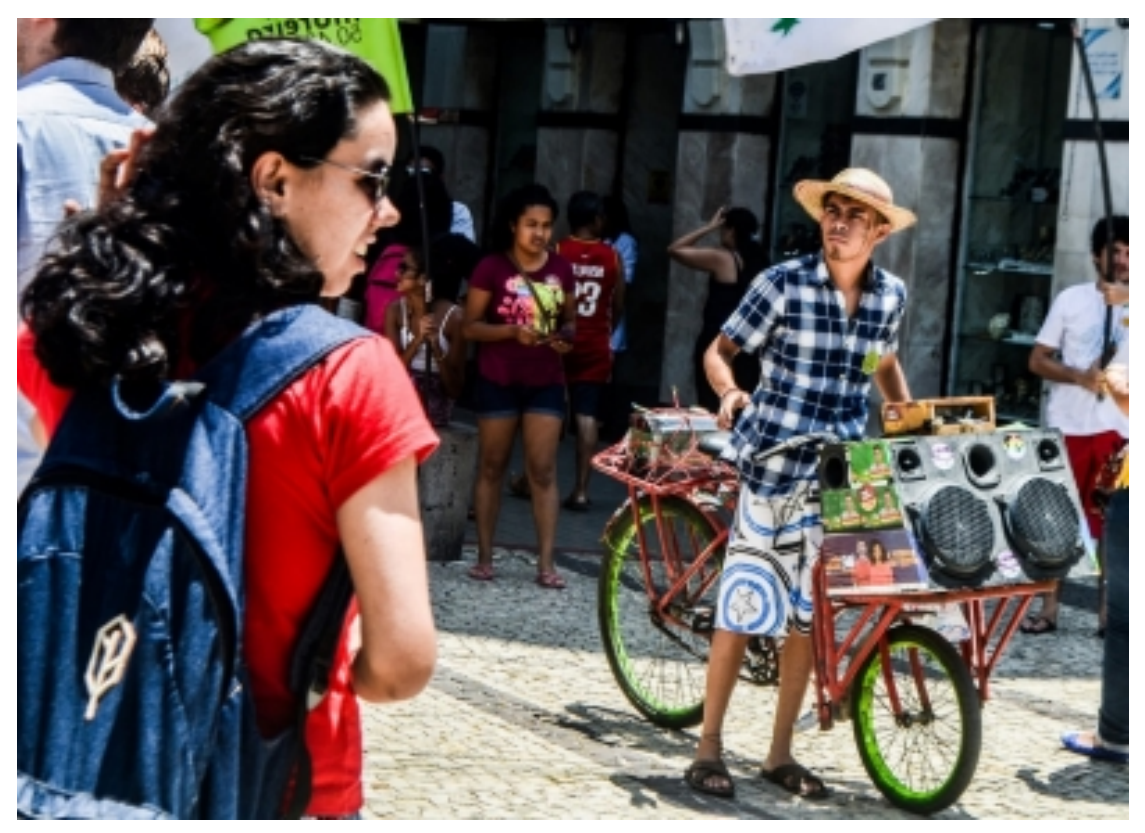

Figura 3. Ecoar o Ferreira Acervo de Pesquisa/Daniel Macêdo, 2016

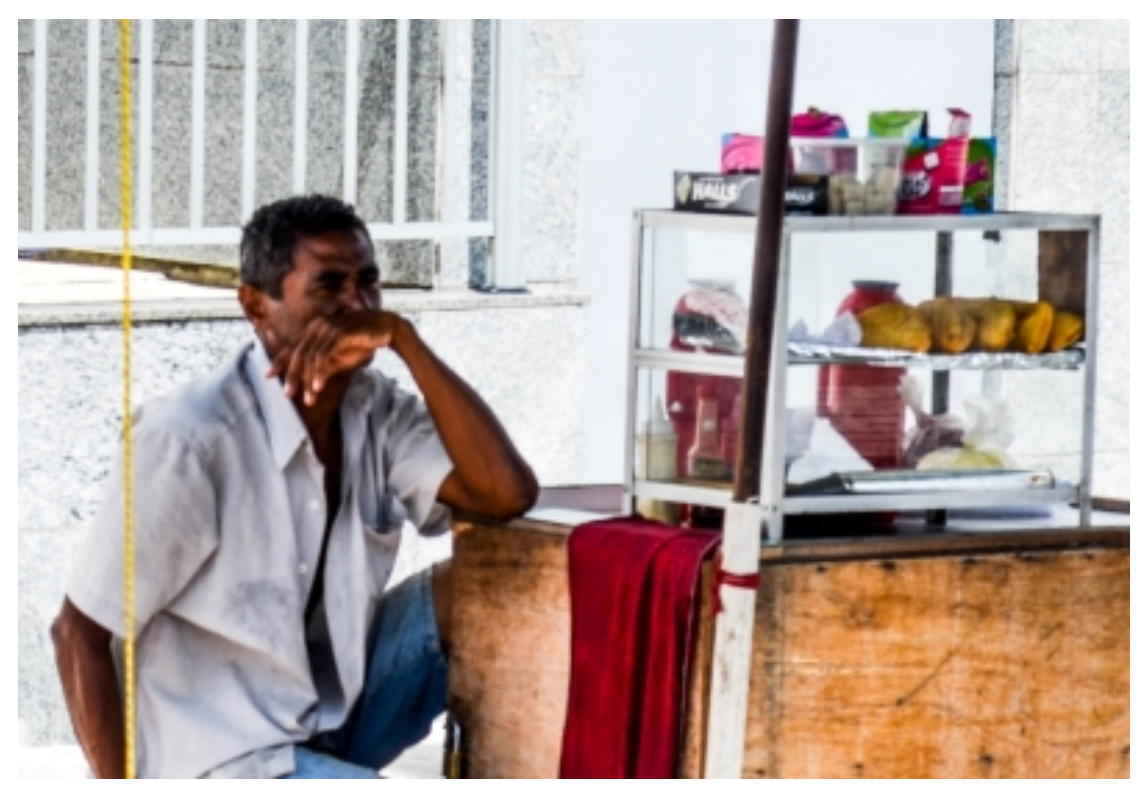

Figura 4. Avistar a General Sampaio Acervo de Pesquisa/Daniel Macêdo, 2017 


\section{Vista}

4181. N.o 8 (2021): Julho - dezembro 2021 | https://doi.org/10.21814/vista.3389

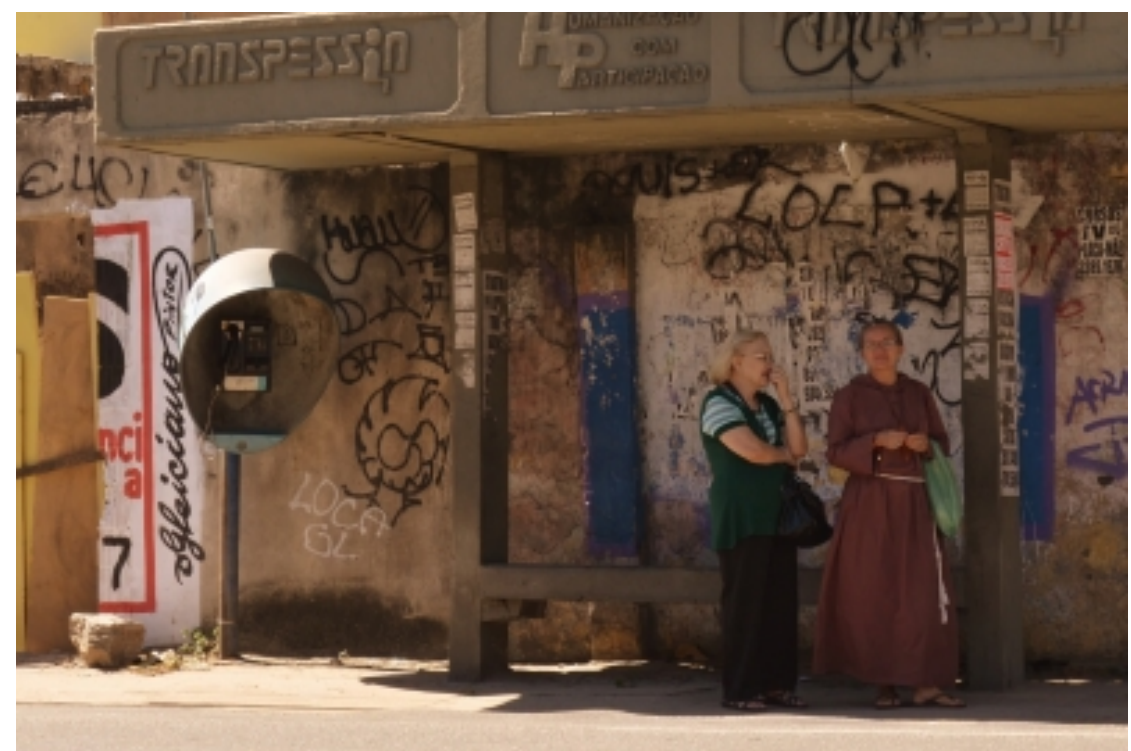

Figura 5. Aguardar a universidade Acervo de Pesquisa/Daniel Macêdo, 2014

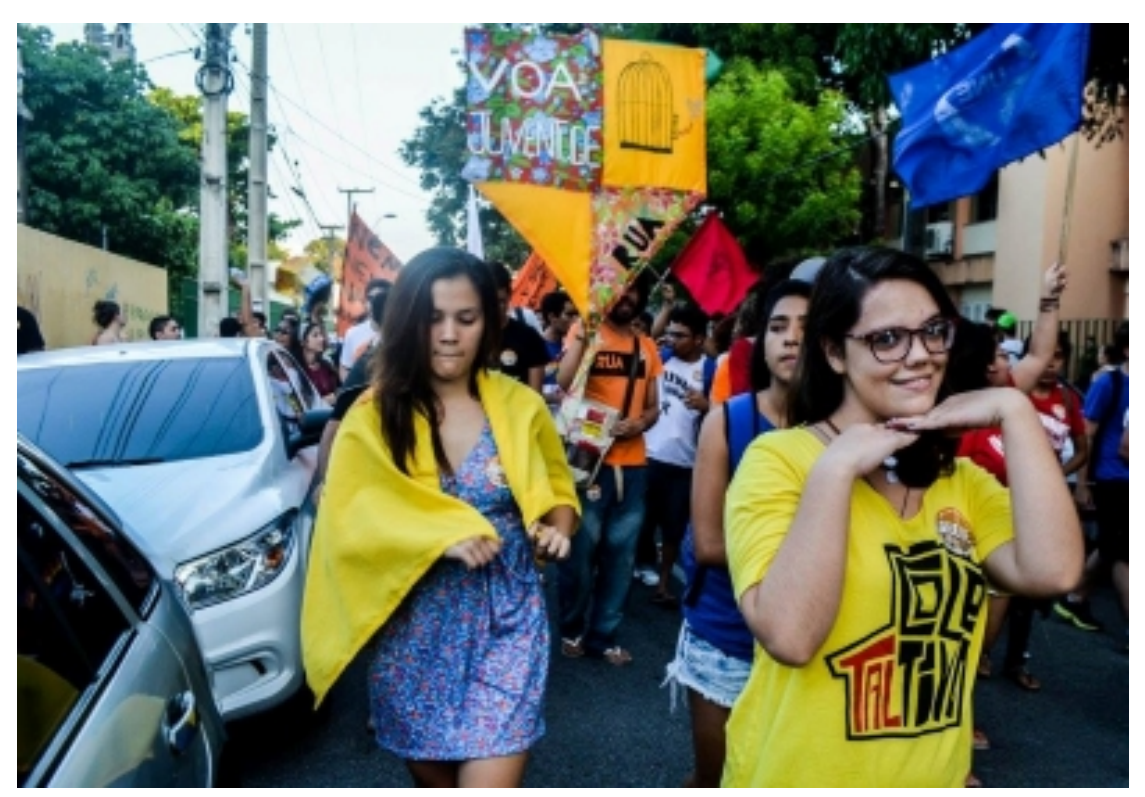

Figura 6. Ocupar a universidade Acervo de Pesquisa/Daniel Macêdo, 2015 


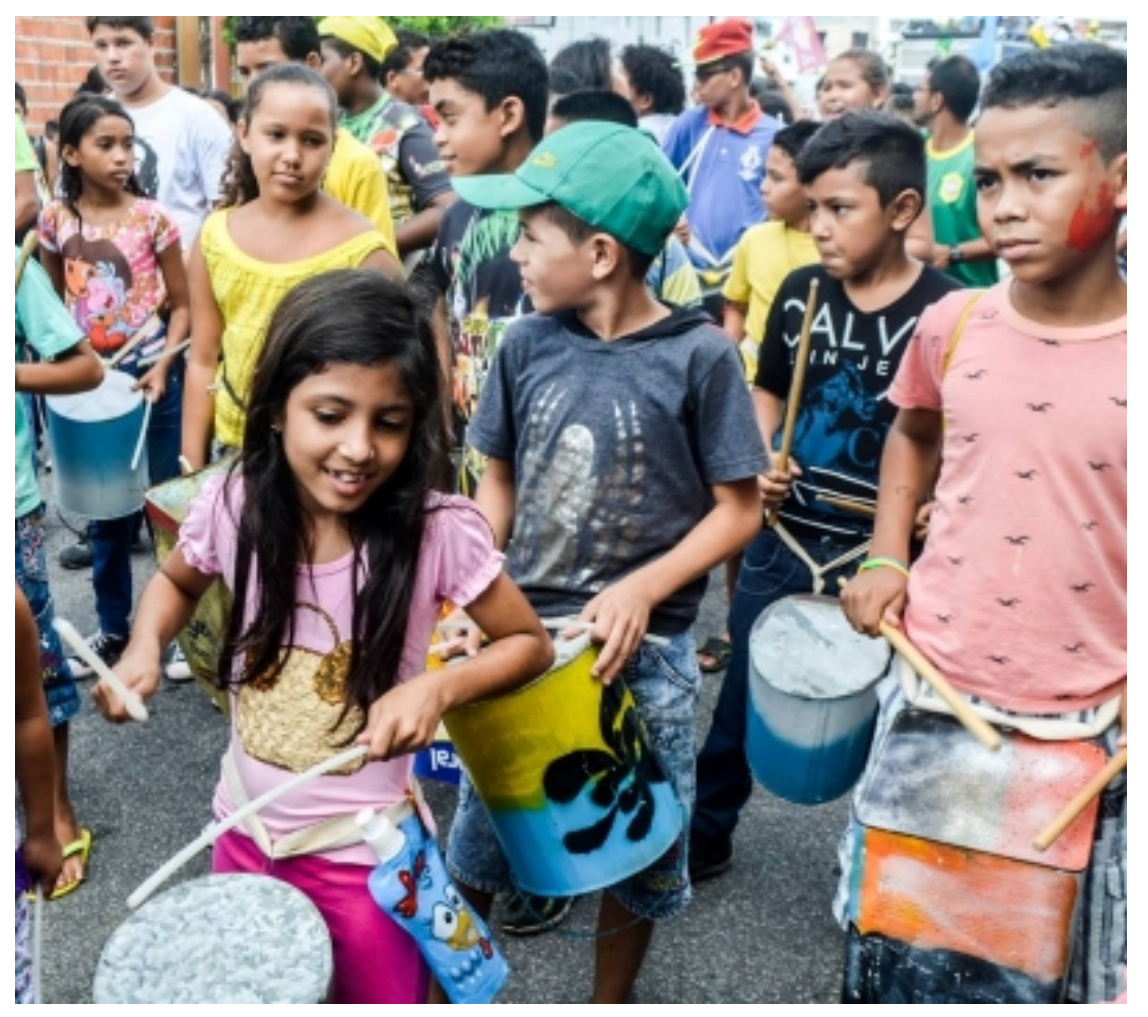

Figura 7. Musicar o coração de Jesus Acervo de Pesquisa/Daniel Macêdo, 2016

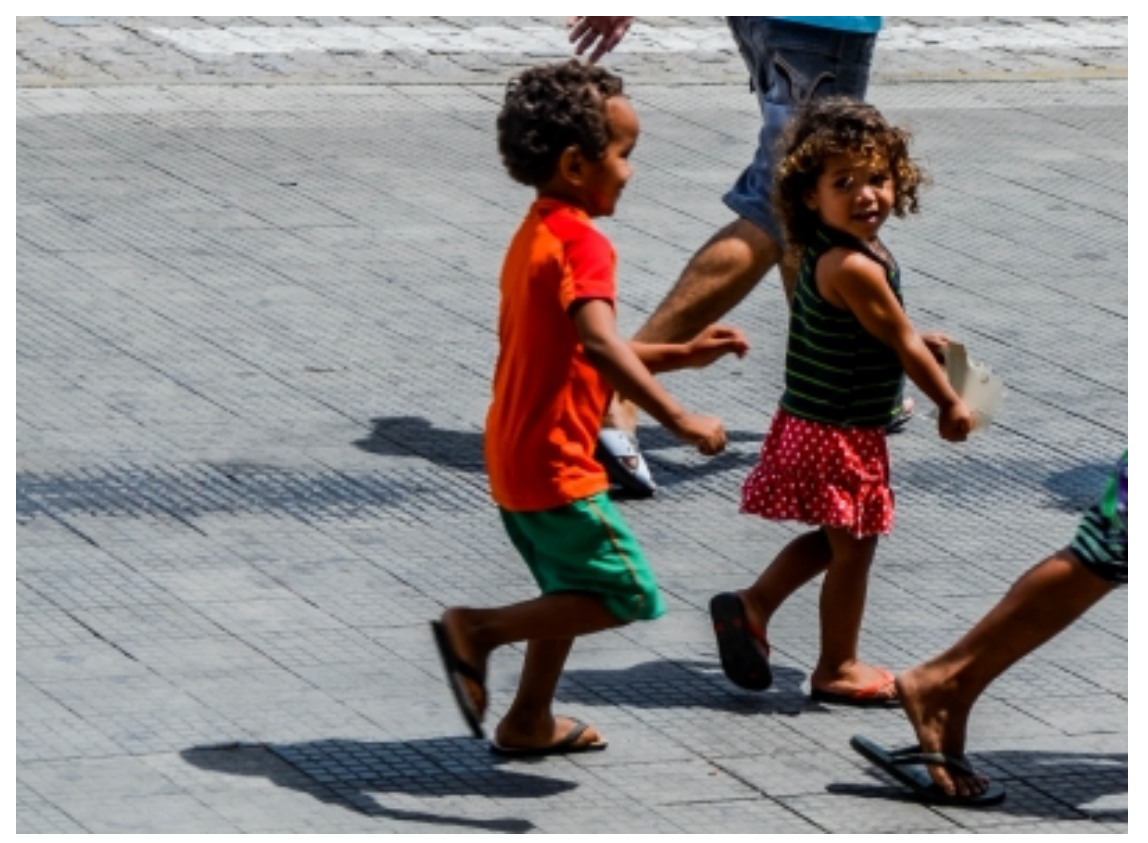

Figura 8. Saltear a General Sampaio Acervo de Pesquisa/Daniel Macêdo, 2018 


\section{Vista}

4617 N. 8 (2021): Julho - dezembro 2021 | https://doi.org/10.21814/vista.3389

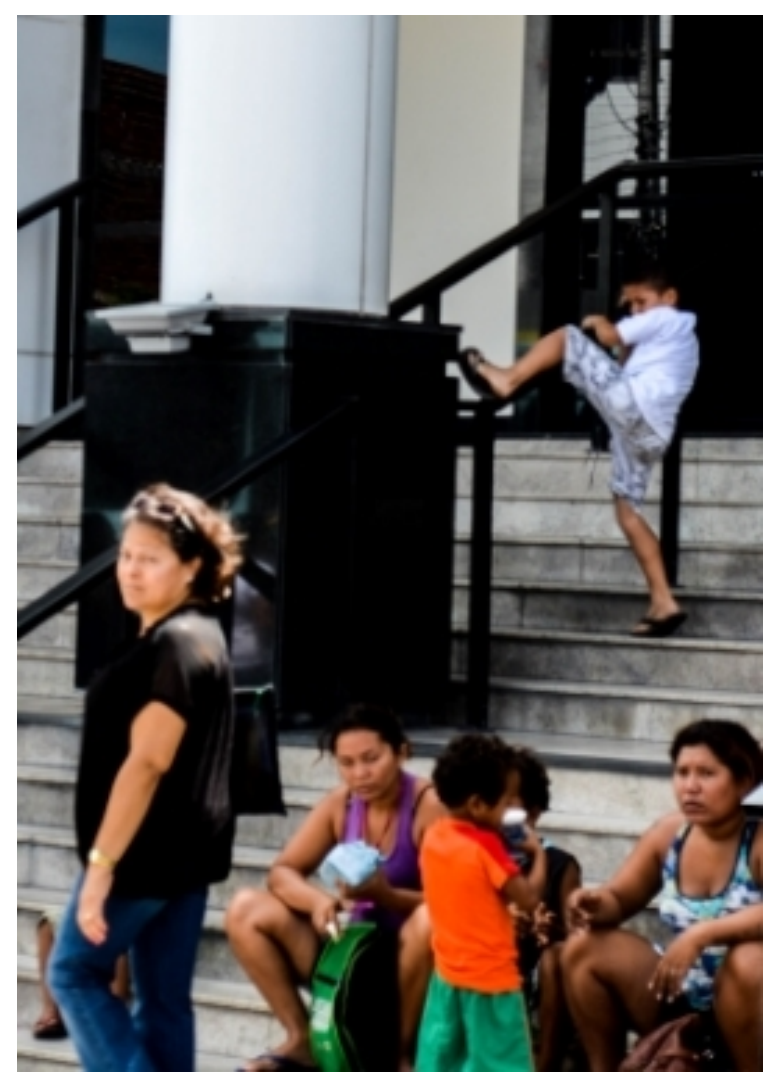

Figura 9. Escorregadias como os corrimãos de uma igreja Acervo de Pesquisa/Daniel Macêdo, 2015

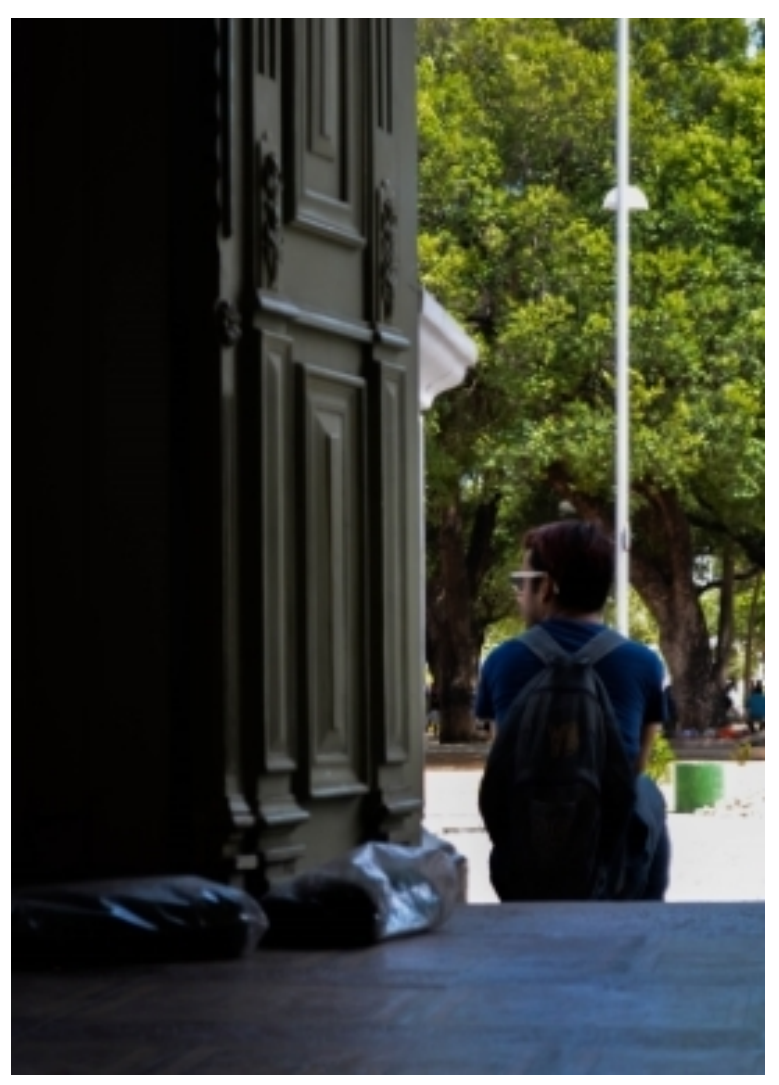

Figura 10. Ver o espetáculo José de Alencar - I Acervo de Pesquisa/Daniel Macêdo, 2014 


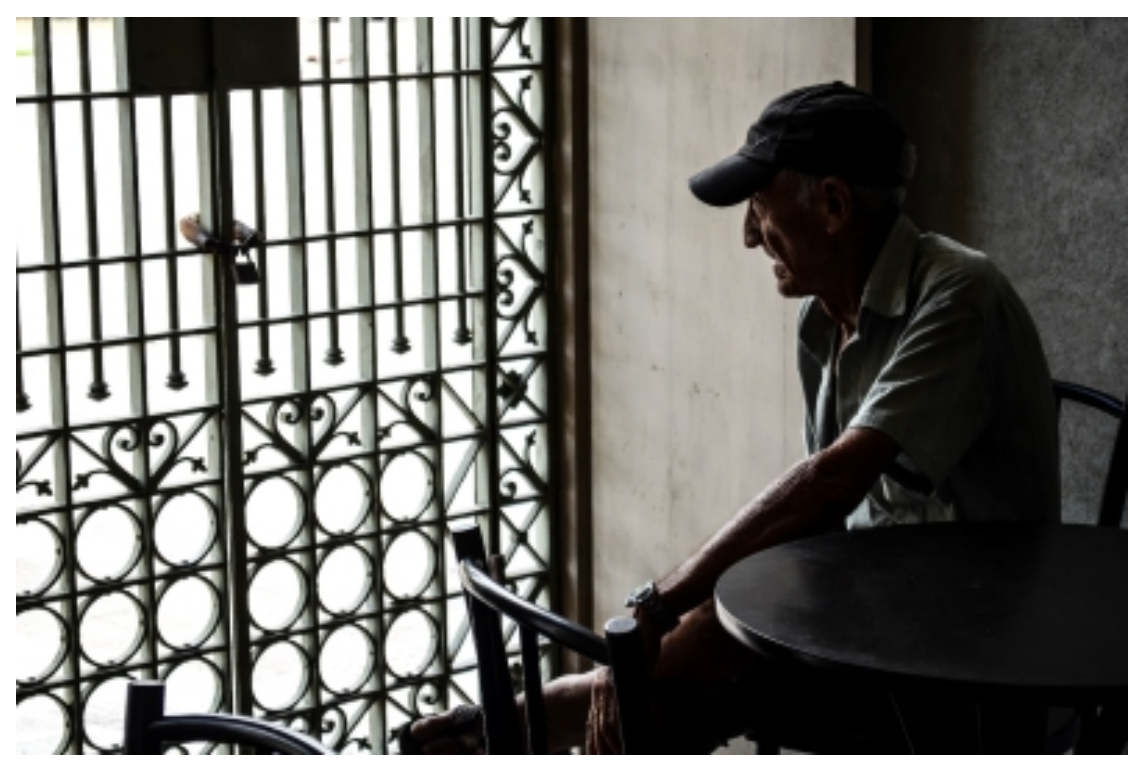

Figura 11. Ver o espetáculo José de Alencar - II Acervo de Pesquisa/Daniel Macêdo, 2018

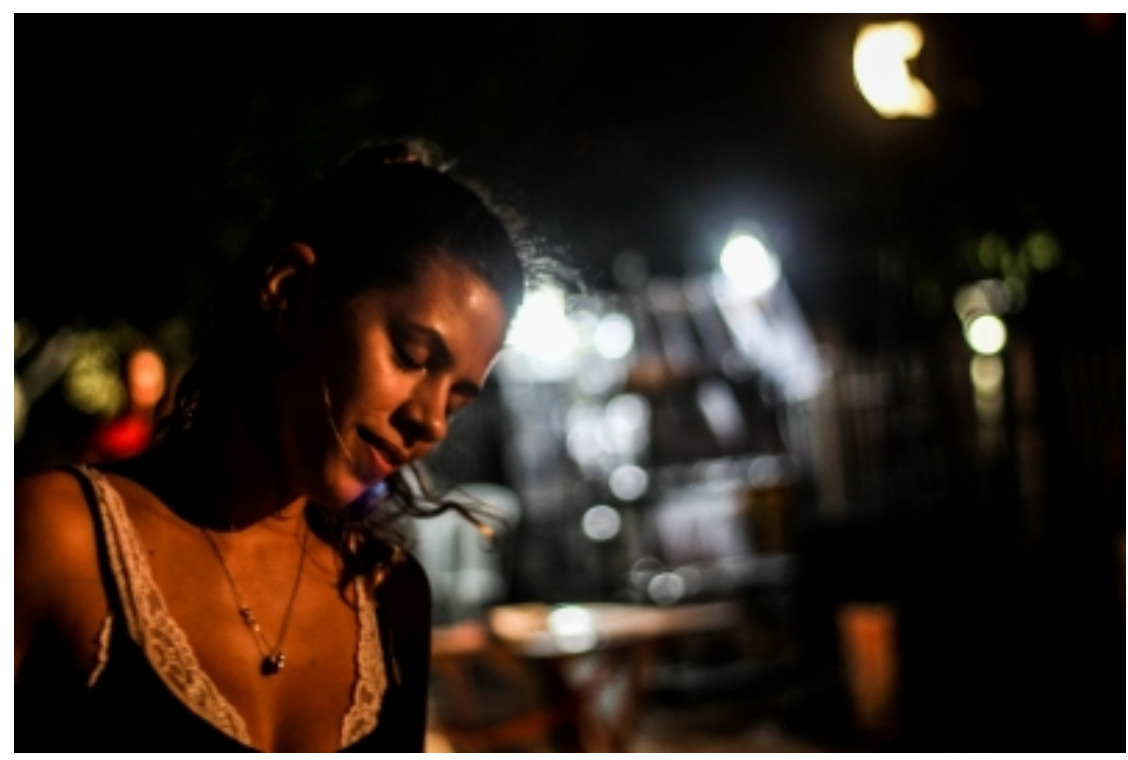

Figura 12. Sentir o Dragão do Mar Acervo de Pesquisa/Daniel Macêdo, 2015 


\section{Vista}

41617 N. 8 (2021): Julho - dezembro 2021 | https://doi.org/10.21814/vista.3389

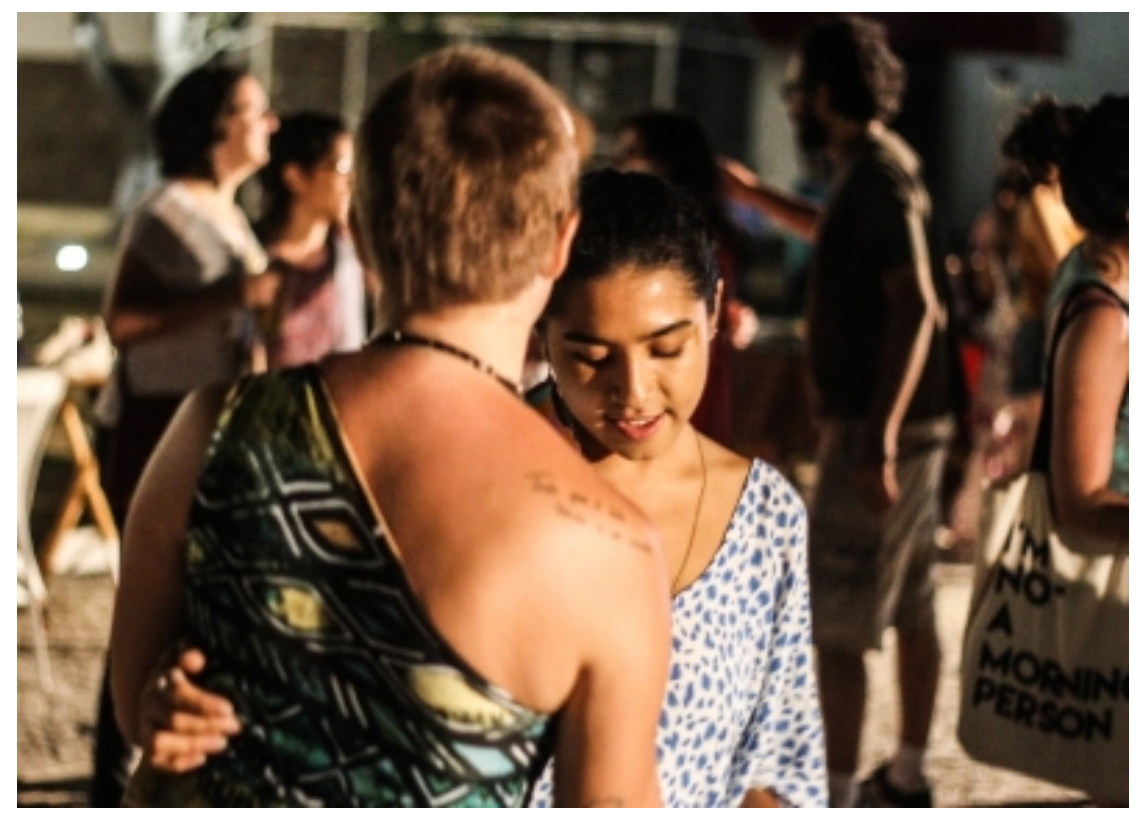

Figura 13. Bailar o Dragão do Mar Acervo de Pesquisa/Daniel Macêdo, 2015

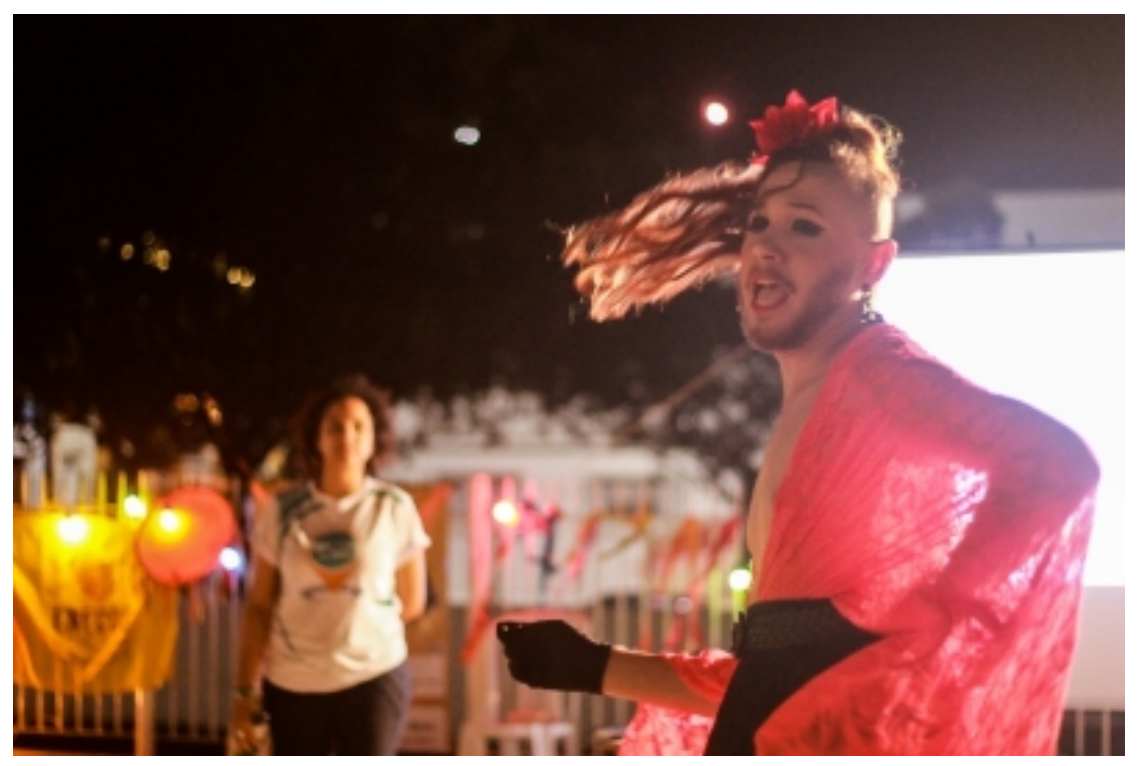

Figura 14. Ser Dragão do Mar Acervo de Pesquisa/Daniel Macêdo, 2016 


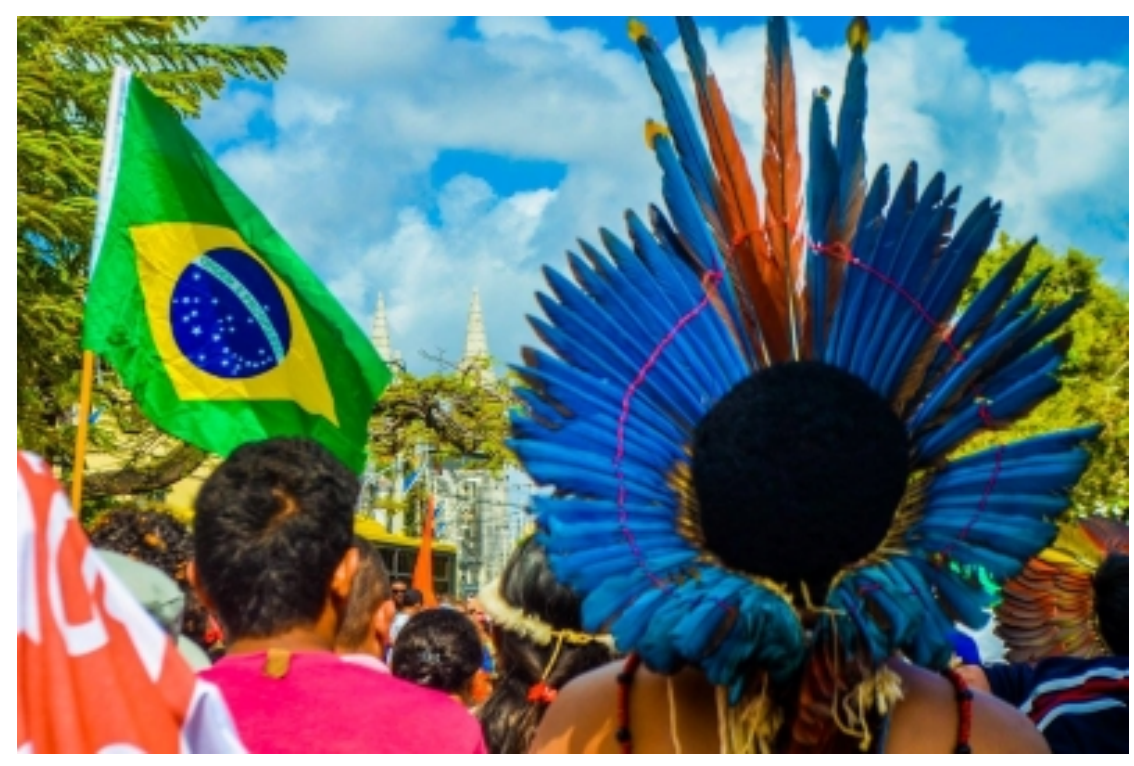

Figura 15. Abrir caminhos na Avenida Dom Manuel Acervo de Pesquisa/Daniel Macêdo, 2015

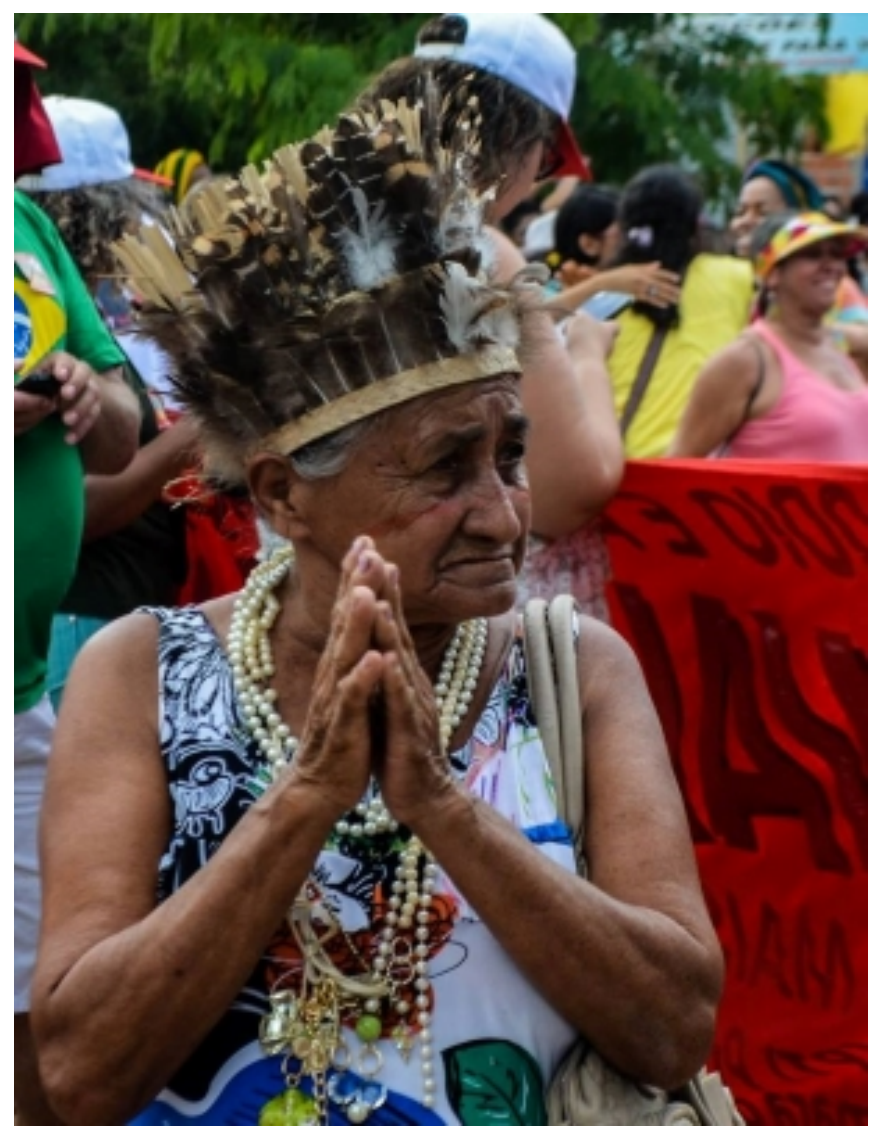

Figura 16. O grito dos excluídos na Avenida Dom Manuel Acervo de Pesquisa/Daniel Macêdo, 2015

Tendo exposto o método curatorial, temos nas imagens dispostas a partilha da leitura das experiências do fotógrafo com o campo. Constituem um convite à imersão no espaço e, fruto de outras observações, instigam ao desenvolvimento de novas imagens em tons de convergência ou divergência sobre o espaço.

Não propomos, aqui, uma discussão pormenorizada da natureza simbólica ou discursiva contida em cada imagem, por entendermos que são produções realizadas com intencionalidade, que dizem 
respeito à experiência, aos trânsitos em detrimento do aspecto estético. Deste modo, ampliamos o convite ao diálogo, a fim de denotar a existência de outras inferências e imaginários conjugados por quem também pratica e compõe o centro de Fortaleza.

Lemos estas fotografias como textualizações de participação ativa no espaço; mais que isso: são atestados das ações que nos afetam a partir da imersão nas ruas e, aqui, versadas em linguagem visual. As fotografias expostas, para além de retratos da territorialidade, conjugam uma faceta sobre as práticas sociais e culturais inerentes a um ambiente complexo e notório em contradições, características de um centro urbano. Não são, no entanto, totalizantes. Ainda que o método em largo tempo e a experiência curatorial - buscando identificar nas imagens as experiências comuns - revelem impregnações das afetações que vivemos no espaço e, assim, revelem um imaginário. Não à toa, outras experiências de pesquisa calcadas em método equivalente podem revelar outros tonais para se perceber o centro da cidade.

Não é todos os dias, por exemplo, que se avista um ato político de rua no centro. Mas o fato é que trata-se de uma ação constante. Nisto, julgamos acertado estabelecer pesquisa em temporadas porque nos permitiu angular o centro em momentos distintos e, assim, complexificar uma noção articulada nesta poética visual sobre o espaço.

Denota-se, portanto, na relação entre o fotógrafo e o espaço, um importante elemento no momento decisivo de compor imagens. Se a ação do flanêur na fotografia bebe do legado de Benjamin (1985/1994, p. 34) ao valorizar o lugar da cidade como agente de colaboração na produção em detrimento do lugar de objeto, é justo notar que esta relação pauta-se pela multiplicidade de experiências que o sujeito-pesquisador pode desenvolver em campo.

\section{Notas Biográficas}

Daniel Paiva de Macêdo Júnior é doutorando em comunicação social na Faculdade de Filosofia e Ciências Humanas da Universidade Federal de Minas Gerais e integrante do Núcleo de Estudos Tramas Comunicacionais: Narrativa e Experiência.

ORCID: https://orcid.org/0000-0002-1415-7792

Email: daniel.3macedo@gmail.com

Morada: Faculdade de Filosofia e Ciências Humanas, Universidade Federal de Minas Gerais Campus Pampulha, Av. Antônio Carlos, no 6627, Belo Horizonte, Brasil

Elian Castro de Machado é doutor em tecnologia educacional pela Indiana University Bloomington (EUA, 1985), docente de Fotojornalismo no Instituto de Cultura e Arte da Universidade Federal do Ceará e foi professor visitante na University of Florida (EUA, 2009).

ORCID: https://orcid.org/0000-0002-2463-0344

Email: elianmachado@ufc.br

Morada: Instituto de Cultura e Arte, Universidade Federal do Ceará, Campus do Pici, Av. Mister Hull, s/n, Fortaleza, Brasil

\section{Referências}

Benjamin, W. (1994). Magia e técnica, arte e política (7.ㄹ ed., S. Rouanet, Trad.). Brasiliense. (Trabalho original publicado em 1985) 


\section{Vista}

41817 N.o 8 (2021): Julho - dezembro 2021 | https://doi.org/10.21814/vista.3389

Fundação Demócrito Rocha. (2021). Anuário do Ceará 2020-2021. O Povo.

Instituto Brasileiro de Geografia e Estatística. (2010). Censo demográfico 2010.

https://biblioteca.ibge.gov.br/visualizacao/livros/liv101728 folder.pdf

Instituto Brasileiro de Geografia e Estatística. (2018). Regiões de influência das cidades.

https://biblioteca.ibge.gov.br/visualizacao/livros/liv101728 folder.pdf

Magnani, J. (2008). Na metrópole: Textos de antropologia urbana. Editora da Universidade de São Paulo.

Martins, J. (2016). Sociologia da fotografia e da imagem. Contexto.

Reis Filho, O. (2017). Imagens insurgentes: Notas sobre a fotografia urbana no Ceará. Discursos

Fotográficos, 13(22), 107-127. https://doi.org/10.5433/1984-7939.2017v13n22p107

Este trabalho está licenciado com uma Licença Creative Commons - Atribuição 4.0 Internacional. 